ISSN: 2394-2258

Available at http://scientificadvances.co.in

DOI: http://dx.doi.org/10.18642/ijamml_7100121823

\title{
THE SUITABLE TIME OF TRAFFIC YELLOW SIGNAL LIGHTS CHANGED IN CHINA
}

\author{
Yuanjie Wang
}

Beijing No. 4 High School, P. R. China

\begin{abstract}
In China, traffic signals at the junction is critical for huge traffic system. In this paper, we will determine the suitable time of traffic yellow signal lights changed after mathematical modelling analysis on problems on the basis of vehicle-dynamics. Furthermore, we got the original data from experiments in order to better cooperate to complete its models.
\end{abstract}

Keywords: automobile vehicle brake, yellow traffic signal lights.

\footnotetext{
${ }^{*}$ Corresponding author.

E-mail address: wyj1559801786@126.com (Yuanjie Wang).
}

Copyright (c) 2017 Scientific Advances Publishers 2010 Mathematics Subject Classification: 05C78.

This research is supported by the Fundamental Research Funds for Central Universities (No. 2652015193).

The paper is guided by Tutors Shali Liu and Jing Li (Beijing No. 4 High School, P. R. China) and Ruisi Li (Beijing No. 39 High School, P. R. China).

Submitted by Haiying Wang.

Received March 31, 2017; Revised April 21, 2017 


\section{The Background of Problems}

The Application, Usage and Registration Rules of Automobile Vehicle Driving License, No. 123 and No. 124 files of Chinese Public Security Ministry, are known as the most strict traffic laws and it was formally implemented in 2013, and it strengthen great penalties for illegally crossing yellow traffic signal lights and even automobile vehicle will should be punished if it still run when traffic yellow signal lights appear.

According to Chinese traffic safety laws on road, traffic yellow signal lights are mainly used to clear motor vehicles at the intersections of roads and make some automobile vehicles which already pass across the vehicle stop lines could quickly run during yellow traffic signal lights time. That is, when yellow traffic signal lights begin, these motor vehicles which have crossed the stop lines have right to continue its running, otherwise, it must stop.

If people do not obey rules about yellow traffic signal lights above, it should be illegal behaviour and 6 scores among drivers' licenses will be punished in accordance with the traffic rules. If more than 12 scores will be lost, these people will seize of lost their licenses. But the new traffic rules will produce many problems. For example, if children or old people are in cars, then drivers cannot immediately brake or speed when yellow traffic signal lights suddenly appear. Thus, there are many a lot of misunderstanding and controversy when the police deals with traffic problems.

In this paper, we will determine the suitable time of yellow traffic signal lights changed according to its scientific analysis of mathematical modelling on the basis of vehicle-dynamics. In addition, we got the original data from experiments in order to better cooperate to complete its models. 


\section{The Solutions of Problems}

In this section, we will study the suitable theoretical time of yellow traffic signal lights changed in China after mathematical models. First, we will give some mathematical model assumptions and consider have some influence factors on the time quantum of yellow traffic signal lights such as speed limit in road, width of road, weight of vehicles, length and direction of vehicle, angles of road plane. To solve the question we must give some useful notations and some special notations as follows.

First, some model assumptions, respectively, (1) Two widths between east and west, north and south of the road are same. And the whole road surface is flat and level. (2) Each automobile vehicle moves straightly when it crosses and the driver should not speed up through the intersections even though he has seen the beginning changing of yellow traffic signal light just for avoiding violating traffic regulations for his excessively speeding. Each automobile vehicle runs straightly and uniformly and the road is very smooth. Second, some special notations are as follows: (1) $n, m$ denote the general quality and length of automobile vehicle, respectively. (2) $v_{0}$ be its limit speeds when automobile vehicle runs across the roads and $\mu_{1}$ be friction factor of the road. (3) $d$ denotes the distance between two stop line of before and after the intersection of the road and $g$ the acceleration of gravity. (4) $T$ denotes the total time of lasting yellow traffic signal lights and $t_{0}$ the response time of the driver, that is, the total time for the driver to think and decide whether he should pass intersections. Let $t_{1}$ be the total time used to stop the vehicle's running and $t_{2}$ be the total time for the driver to be used to run the distance $d+m$ by its speed $v_{0}$.

Now we begin to establish its mathematical models as follows. When each automobile vehicle crosses through the intersection of a road, there is maybe two possibilities, depending on whether the driver slams the brakes before the stop line. 
Case 1. If the driver decides to brakes before the stop line, then the lasting time of yellow traffic signal lights should not less than the time from having deciding to stopping the line, that is, the total of the response time and the braking time (see Figure 1).

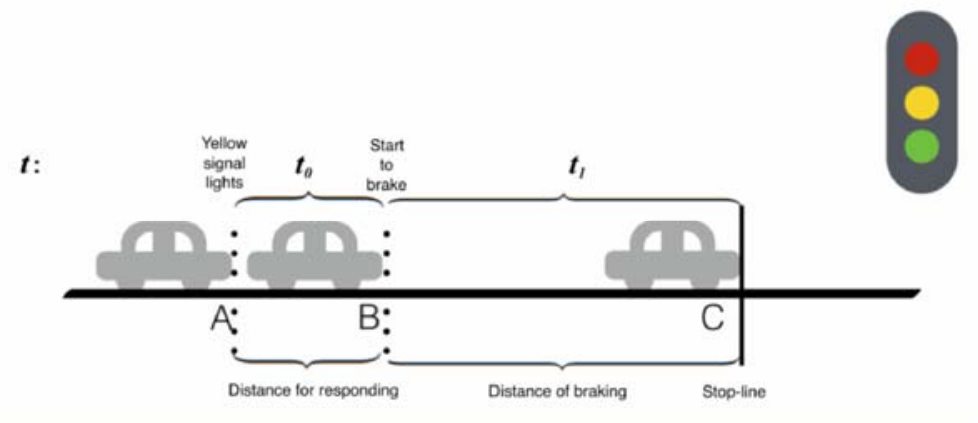

\section{Figure 1.}

Case 2. If the driver decides to pass through crossroads, then the lasting time of yellow traffic signal lights changed should not less than the time from having decision to running through the opposite intersection and then getting the space after opposite stopping line, that is, the total of the response time and the crossing time (see Figure 2).

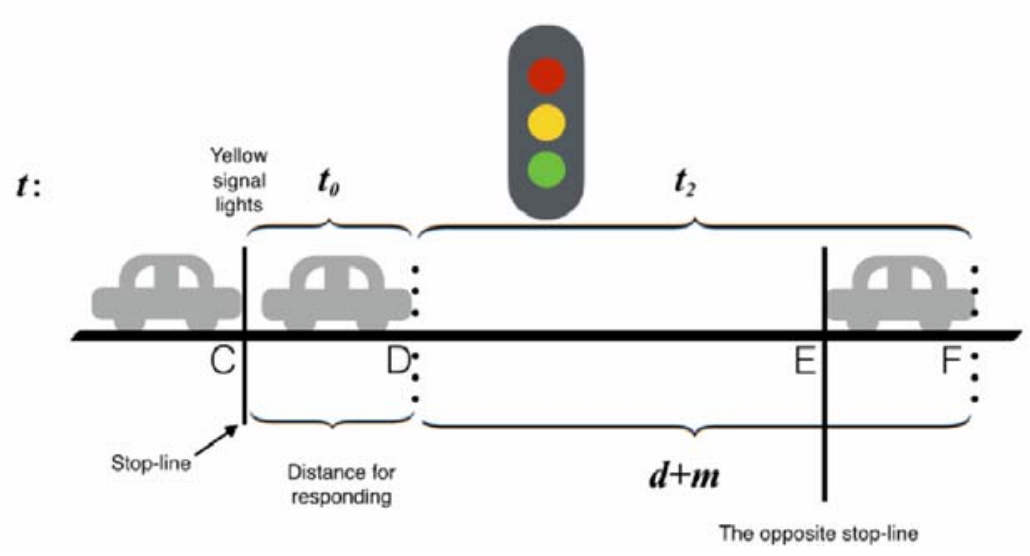

Figure 2. 
Based on the analysis and assumptions above, we have $T=\max \left\{t_{0}+t_{1}, t_{0}+t_{2}\right\}$. According to vehicle-dynamics, we deduce $t_{1}$ from the equations as follows:

$$
\left\{\begin{array}{l}
-\mu_{1} n g=n \cdot \frac{d v}{d t}, \\
\left.v\right|_{t=0}=v_{0}
\end{array}\right.
$$

where $t_{2}=\frac{d+m}{v_{0}}$. Then we can solve the equations and obtain $v=-\mu_{1} g t+v_{0}$. Since $0=-\mu_{1} g t+v_{0}$, we have $t_{1}=\frac{v_{0}}{\mu \mathrm{g}}$. Therefore, the total time of lasting yellow signal lights should be decided by the limit speed and road width, then $T=\max \left\{t_{0}+\frac{v_{0}}{\mu g}, t_{0}+\frac{d+m}{v_{0}}\right\}$. The maximum static friction is greater than the sliding friction between the same materials. After installing Anti-lock Braking System (ABS), the friction between vehicles' wheels and the ground of each vehicle is the maximum static friction.

Its principle is roughly that its automatic system should control the size of the braking force and make its wheels unlocked so that there is no relative movement with the ground and maximize its static friction to brake the vehicle. That is, it is not directly brake the vehicle to death.

But actually when the vehicles cross the intersection, it does not slam the brakes, but under the conditions of more comfortable acceleration. Below, the author does feed experiments personally with own private car and records the data (see Appendix).

During these experimental processes, the author runs his car on more horizontal road plane and more straightly with each speed by 20, 30, 40, 50 , and 60 kilometers per hour in the brake test, respectively. 
The author did this experiment 3-6 times per hour, and eliminated obviously extreme data and record the normal ones in the table below. Then we use these data and the formula (1) to calculate the acceleration and speed of the equivalent friction factor $\mu_{1}$. Note that more $60 \mathrm{~km} / \mathrm{h}$ speeds will be dangerous to do experiments. Then the author choose experimental speeds under $60 \mathrm{~km} / \mathrm{h}$.

\begin{tabular}{|c|c|c|c|c|}
\hline $\begin{array}{c}\text { Speed }\left(\mathrm{km} \cdot \mathrm{h}^{-1}\right) \\
\left(\mathrm{m} \cdot \mathrm{s}^{-1}\right)\end{array}$ & $\begin{array}{c}\text { Brake-time } \\
(\mathrm{s})\end{array}$ & $\begin{array}{c}\text { Brake-distance } \\
(\mathrm{m})\end{array}$ & $\begin{array}{c}\text { Acceleration } \\
\left(\mathrm{m} / \mathrm{s}^{2}\right)\end{array}$ & $\begin{array}{c}\text { Equivalent } \\
\text { friction factor }\end{array}$ \\
\hline $20(5.556)$ & 3.32 & 8.2 & 1.88 & 0.19 \\
\hline $30(8.333)$ & 4.31 & 17.5 & 1.98 & 0.20 \\
\hline $40(11.111)$ & 5.06 & 27.25 & 2.19 & 0.22 \\
\hline $50(13.889)$ & 6.32 & 43.6 & 2.21 & 0.22 \\
\hline $60(16.667)$ & 8.25 & 64.5 & 2.14 & 0.21 \\
\hline
\end{tabular}

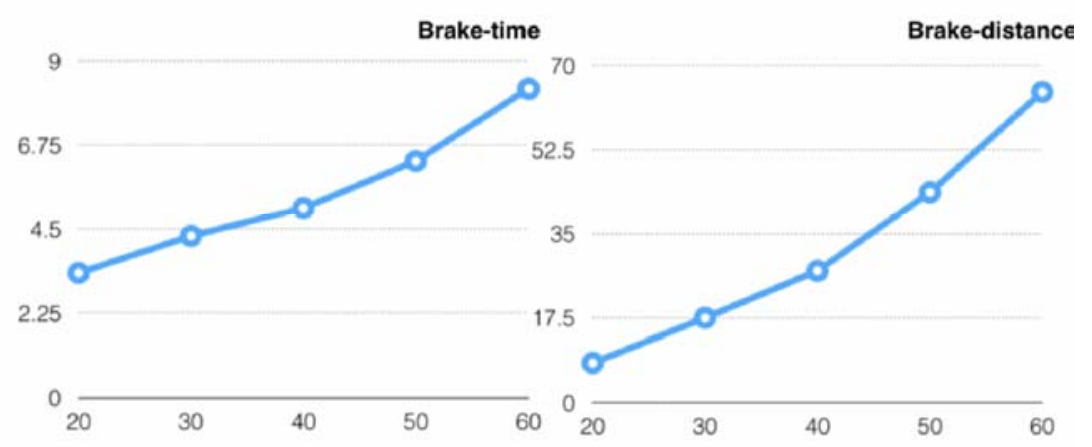

Table 1. Data records.

After analysis on these data, we obtain the approximate value 0.21 as the equivalent friction factor. Obviously, according to some actual situations, we can get further improvement to the models. 


\section{References}

[1] Guo Mu, Zhang Xinyu and Li Deyi, Traffic light detection and recognition for autonomous vehicles, The Journal of China Universities of Posts and Telecommunications 22(1) (2015), 50-56.

[2] V. John and K. Yoneda, Traffic light recognition in varying illumination using deep learning and saliency map, IEEE International Conference on Intelligent Transportation Systems (2014), 2286-2291.

[3] M. Diaz Cabrera, P. Cerri and P. Medici, Robust real-time traffic light detection and distance estimation using a single camera, Expert Systems with Applications 42(8) (2015), 3911-3923. 


\section{Appendix}

\begin{tabular}{|c|c|c|c|c|c|c|}
\multicolumn{9}{|c|}{ Speed $\mathbf{2 0 k m} / \mathbf{h}$} \\
\hline Times & 1 & 2 & 3 & 4 & 5 & 6 \\
\hline Brake-time(s) & 3.16 & 3.12 & 3.61 & 3.64 & 3.07 & \\
\hline Brake-distance(m) & 7.7 & 8.0 & 8.5 & 8.7 & 8.1 & \\
\hline
\end{tabular}

Speed $30 \mathrm{~km} / \mathrm{h}$

\begin{tabular}{|c|c|c|c|c|c|c|}
\hline Times & 1 & 2 & 3 & 4 & 5 & 6 \\
\hline Brake-time(s) & 4.43 & 4.61 & 4.03 & 4.11 & 3.97 & 4.71 \\
\hline Brake-distance(m) & 17.7 & 19.3 & 16.8 & 16.9 & 14.9 & 19.4 \\
\hline
\end{tabular}

Speed $40 \mathrm{~km} / \mathrm{h}$

\begin{tabular}{|c|c|c|c|c|c|}
\hline Times & 1 & 2 & 3 & 4 & 5 \\
\hline Brake-time(s) & 4.79 & 4.91 & 7.74 (rejection) & 5.91 & 4.63 \\
\hline Brake-distance(m) & 25.5 & 27.9 & 40.0 (rejection) & 30.1 & 25.5 \\
\hline
\end{tabular}

Speed $50 \mathrm{~km} / \mathrm{h}$

\begin{tabular}{|c|c|c|c|c|c|c|}
\hline Times & 1 & 2 & 3 & 4 & 5 & 6 \\
\hline Brake-time(s) & 8.82 (rejection) & 6.07 & 6.37 & 6.52 & 9.12 (rejection) & 6.32 \\
\hline Brake-distance(m) & 61.0 (rejection) & 39.7 & 43.9 & 43.8 & 63.5 (rejection) & 4.70 \\
\hline
\end{tabular}

Speed $60 \mathrm{~km} / \mathrm{h}$

\begin{tabular}{|c|c|c|c|}
\hline Times & 1 & 2 & 3 \\
\hline Brake-time(s) & 8.70 & 7.96 & 8.09 \\
\hline Brake-distance(m) & 69.0 & 60.0 & 64.5 \\
\hline
\end{tabular}

